\title{
EDITORIAL
}

\section{Uncertainty in water resources: introduction to the special column}

\author{
S.R. FASSNACHT $(\bowtie)^{1,2,3}$, R.W. WEBB ${ }^{4,5}$, M. MA ${ }^{6}$ \\ 1 ESS-Watershed Science, Colorado State University, Fort Collins, CO 80523-1476, USA \\ 2 Cooperative Institute for Research in the Atmosphere, Fort Collins, CO 80523-1375, USA \\ 3 Natural Resources Ecology Laboratory, Fort Collins, CO 80523-1499, USA \\ 4 Institute of Arctic and Alpine Research, University of Colorado Boulder, Boulder, CO 80309-0450, USA \\ 5 now with Department of Civil, Construction, and Environmental Engineering, University of New Mexico, Albuquerque, NM 87131, USA \\ 6 Research Base of Karst Eco-environments at Nanchuan in Chongqing, Ministry of Nature Resources, School of Geographical Sciences, Southwest \\ University, Chongqing 400715, China
}

(C) Higher Education Press and Springer-Verlag GmbH Germany, part of Springer Nature 2018

\section{Introduction}

Uncertainty is a defining problem in the understanding of earth systems, especially for water resources (Guillaume et al., 2017). The word "uncertainty" can have a variety of meanings (Montanari, 2007; Beven, 2016). Typically, we only understand processes in the confines of laboratory experiments, on a very fine scale in the field, or in vague generalities. This is often the case because the processes are not well understood, or there is not enough data at the appropriate resolution or over a sufficient extent. Scaling issues occur at both spatial and temporal resolution leaving the scientist with imperfect knowledge of a system and poorly defined errors when evaluating it.

Common approaches to address uncertainty are to collect more data, combine a variety of datasets, and/or to model the systems. There are highly monitored study areas with much data (e.g., Stottlemyer and Troendle, 1999; Western et al., 1999; Tromp-van Meerveld et al., 2008; Kampf and Burges, 2010; Winstral and Marks, 2014), but they are few and far between. This has led to efforts that combine a variety of datasets, especially from remote sensing (e.g., Kim et al., 2015; Dozier et al., 2016). Most efforts now include a modeling component.

The famous statistician George Box wrote that "all models are wrong, but some are useful" (Box and Draper, 1987). Models are often used without a complete representation of all of the processes. While the simple solution is often preferred (Sober, 2015), some models, such as the Rational Method (Kuichling, 1889), are so simplistic this limits the applicability. Some models are used without a full evaluation of the underlying assumptions and are considered a black box (Borgonovo et al., 2017). Model performance can be difficult to evaluate, especially where we have little to no information available for model evaluation (Hrachowitz et al., 2013).

There are various different modeling approaches to address and evaluate uncertainty (Nearing et al., 2016). Probabilistic approaches can be applied to analyze data (e.g., Zargar et al., 2012) or to run a model, such as Monte Carlo random (Hastings, 1970) or Latin hypercube (McKay et al., 1979) parameter selection. Ensemble model approaches use the range of observed data as input to produce probabilistically output of possible realizations (Twedt et al., 1977). As Pliny the Elder stated "the only certainty is that nothing is certain," which has led various assessments of hydrological uncertainty (e.g., Hrachowitz et al., 2013; Carsteanu et al., 2016).

This special column of Frontiers of Earth Science started as a symposium on Uncertainty in Water Resources and Environmental Sustainability that was held at Southwest University in Chongqing, China on October 26th, 2016. The focus was any part of the globe with a physical, ecological, or social science perspective, or any combination thereof. The goals of this special column were to provide insight into methods of quantifying uncertainty, the estimation of uncertainty in regions that have not been extensively studied, and the incorporation of uncertainty in models. One

Received September 18, 2018

E-mail: Steven.Fassnacht@colostate.edu 
invited paper (Nearing and Gupta, this issue) and eight regular papers appear in the issue. The papers are divided into the topics of modeling, snow, and other applications. The first Special Issue on the theme of Water and Environmental Sustainability focused on Headwaters Regions and appeared in 2017 (Fassnacht et al., 2017).

\section{Overview of special column papers}

This special column begins with a concept paper (Nearing and Gupta, this issue) that defines the term uncertainty in the context of hydrological modeling, and ergo other system modeling, comparing the idea of multi-model ensembles to a theoretical information science approach. The authors make the important point that a sensitivity analysis performed within a model does not assess uncertainty, but rather only assesses that specific model formulation. This is contrary to Saltelli and Funtowicz (2014) who unfortunately equate the two. Nearing and Gupta (this issue) do highlight that a model sensitivity analysis is relevant to understand the architecture and possibly the limitation of a particular model. They also encourage the recommendation by Saltelli and Funtowicz (2014) that models need to be more rigorously tested and evaluated, especially when used to inform policy. The paper by Nearing and Gupta (this issue) presents a philosophical approach to modeling that may enable the conceptualization and creation of robust models to address more complex systems.

Two papers focused on modeling. Four uncertainty analysis algorithms were applied in the Soil and Water Assessment Tools (SWAT) eco-hydrological model to quantify different source of uncertainties (especially parameter uncertainty) and evaluate their performance (Rafiei Emam et al., this issue). These four algorithms were Generalized Likelihood Uncertainty Estimation (GLUE), Sequential Uncertainty Fitting (SUFI), Parameter Solution method (ParaSol) and Particle Swarm Optimization (PSO). The results suggested using SUFI-2 initially to set the parameter ranges, and further use PSO for final analysis (Rafiei Emam et al., this issue).

The uncertainties associated with land surface processes were investigated through comparisons of two land surface models with a coupled atmosphere-land modeling system (Suzuki and Zupanski, this issue). These platforms were used with a maximum likelihood ensemble filter data assimilation for 24-hour prediction simulations in Siberia in 2013. Results of this study show that the inclusion of a multiple snow-layer model is beneficial for reducing the uncertainties associated with snow depth and change in snow depth. Four other papers analyzed different aspects of uncertainty associated with snow.

To better constrain snow depth sampling strategy for the purpose of remote sensing ground-truthing, Fassnacht et al. (this issue) analyzed fine resolution snow depth field measurements with $30 \mathrm{~m}$ pixels over $1 \mathrm{~km}^{2}$ areas. They found that using only three measured snow depths resulted in large errors for some of these pixels and that between 3 and 6 point measurements was optimal to achieve an acceptable error of $5 \%$. One location was measured for two years prior to peak accumulation, showing little to no inter-annual consistency in the mean and standard deviation.

Two papers investigated snow measurements through remote sensing. O'Leary et al. (this issue) focused on the Cascade Mountains in the Western USA to assess the onset of snowmelt. Using the MODerate-resolution Imaging Spectroradiometer (MODIS) data, they derived snowmelt timing maps to assess that the 2015 snowmelt began 41 days earlier than the 2001 to 2015 mean, and a quarter of their study domain melted out more than two months earlier than average.

Evaluating both MODIS and Visible Infrared Imaging Radiometer Suite (VIIRS) data, Appel (this issue) quantified uncertainty in estimating fractional snow covered area (SCA) from multiple sensors. The Normalized Difference Snow Index (NDSI) was used to estimate fractional SCA. The MODIS and VIIRS based snow maps, at a 500 and $375 \mathrm{~m}$ resolution, respectively, were compared to the 30-m binary SCA derived from Landsat data.

The uncertainty of snowpack sublimation estimates using the bulk aerodynamic flux equation was quantified through modeling sublimation for three water years at West Glacier Lake watershed in Wyoming (Hultstrand and Fassnacht, this issue). A Monte Carlo analysis evaluated the sensitivity of modeled sublimation to uncertainties within the input variables and parameters, resulting in a mean cumulative uncertainty of $41 \%$. The measurement height, aerodynamic roughness length, and relative humidity were the three parameters that accounted for $74 \%$ to $84 \%$ of the sublimation uncertainty.

A gross primary productivity (GPP) dataset derived from MODIS was used by Huang et al. (this issue) to assess global maize croplands. Point data from seven eddy covariance (EC) flux tower sites in China, France, Germany, and USA were used as ground-truth to assess the GPP data. A light use efficiency model was recalibrated with the EC data and applied with meteorological variables to improve the global GPP estimates. The occurrence of a continuous rainy season at the German EC site created noise that was identified to further improve the calibration.

The sediment distribution downstream of the Three Gorges Reservoir (TGR) on the Yangtze River was investigated from 1987 to 2014 to capture conditions prior to and after reservoir impoundment in 2003 (Li et al., this 
issue). Results of this study display the control that reservoir discharge has on sediment transport. Since the TGR impoundment sediment transport has decreased. Sediment discharge increases as distance from TGR increases indicating sediment transport being fed by riverbed scouring with varying dynamics in the downstream reaches since impoundment.

Acknowledgements We thank the Confucius Institute Headquarters (Hanban) for supporting the Colorado State University Confucius Institute and the Water and Environmental Sustainability symposium series. Dr. Xiaoyu Chen of Higher Education Press and Professor Qing Zhao of East China Normal University for their help in coordinating this special column. We also acknowledge the efforts of Professor Hoshin Gupta of the University of Arizona for his ongoing discussion of uncertainty across the hydrology community.

\section{References}

Beven K J (2016). Facets of uncertainty: epistemic uncertainty, nonstationarity, likelihood, hypothesis testing, and communication. Hydrol Sci J, 61 (9): $1652-1665$

Borgonovo E, Lu X, Plischke E, Rakovec O, Hill M C (2017). Making the most out of a hydrological model data set: sensitivity analyses to open the model black-box. Water Resour Res, 53(9): 7933-7950

Box G E P, Draper N R (1987). Empirical Model-Building and Response Surfaces. John Wiley and Sons, 1-688

Carsteanu A, Eris E, Volpi E, Weijs S (2016). Preface - Special issue: facets of uncertainty. Hydrol Sci J, 61(9): 1555-1556

Dozier J, Bair E H, Davis R E (2016). Estimating the spatial distribution of snow water equivalent in the world's mountains. WIREs Water, 3(3): 461474

Fassnacht S R, Webb R W, Sanford W E (2017). Headwater regions-Physical, ecological, and social approaches to understand these areas: introduction to the special issue papers. Front Earth Sci, 11(3): 443-446

Guillaume J H A, Helgeson C, Elsawah S, Jakeman A J, Kummu M (2017). Toward best practice framing of uncertainty in scientific publications: a review of water resources research abstracts. Water Resour Res, 53(8): 6744-6762

Hastings W K (1970). Monte Carlo sampling methods using Markov chains and their applications. Biometrika, 57(1): 97-109

Hrachowitz M, Savenije H H G, Blöschl G, McDonnell J J, Sivapalan M, Pomeroy J W, Arheimer B, Blume T, Clark M P, Ehret U, Fenicia F, Freer J E, Gelfan A, Gupta H V, Hughes D A, Hut R W, Montanari A, Pande S, Tetzlaff D, Troch P A, Uhlenbrook S, Wagener T, Winsemius H C, Woods R A, Zehe E, Cudennec C (2013). A decade of predictions in Ungauged Basins (PUB) - A review. Hydrol Sci J, 58(6): 1198-1255

Kampf S K, Burges S J (2010). Quantifying the water balance in a planar hillslope plot: effects of measurement errors on flow prediction. J Hydrol (Amst), 380(1-2): 191-202

Kim S, Parinussa R M, Liu Y Y, Johnson F M, Sharma A (2015). A framework for combining multiple soil moisture retrievals based on maximizing temporal correlation. Geophys Res Lett, 42(16): 6662-6670

Kuichling E (1889). The relation between the rainfall and the discharge of sewers in populous districts. Trans Am Soc Civ Eng, 20: 1-56

McKay M D, Beckman R J, Conover W J (1979). A Comparison of three methods for selecting values of input variables in the analysis of output from a computer code. Technometrics, 21(2): 239-245

Montanari A (2007). What do we mean by 'uncertainty'? The need for a consistent wording about uncertainty assessment in hydrology. Hydrol Processes, 21(6): 841-845

Nearing G S, Tian Y, Gupta H V, Clark M P, Harrison K W, Weijs S V (2016). A philosophical basis for hydrological uncertainty. Hydrol Sci J, 61(9): 1666-1678

Saltelli A, Funtowicz S (2014). When all models are wrong. Issues Sci Technol, XXX(2): 79-85

Sober E (2015). Ockham's Razors: A User's Manual. Cambridge University Press, 1-322

Stottlemyer R, Troendle C A (1999). Effect of subalpine canopy removal on snowpack, soil solution, and nutrient export, Fraser Experimental Forest, CO. Hydrol Processes, 13(14-15): 2287-2299

Tromp-van Meerveld H J, James A L, McDonnell J J, Peters N E (2008). A reference data set of hillslope rainfall-runoff response, Panola Mountain Research Watershed, United States. Water Resour Res, 44(6): W06502

Twedt T M, Schaake J C Jr, Peck E L (1977). National weather service extended streamflow prediction. Proceedings of the 45th Annual Western Snow Conference, April 19-21, 1977, Albuquerque NM, 52-57

Western A W, Grayson R B, Green T R (1999). The Tarrawarra project: high resolution spatial measurement, modelling and analysis of soil moisture and hydrological response. Hydrol Processes, 13(5): 633-652

Winstral A, Marks D (2014). Long-term snow distribution observations in a mountain catchment: assessing variability, time stability, and the representativeness of an index site. Water Resour Res, 50(1): 293-305

Zargar A, Sadiq R, Naser G, Khan F I, Neumann N N (2012). Dempster-Shafer theory for handling conflict in hydrological data: case of snow water equivalent. J Comput Civ Eng, 26(3): 434-447 


\section{Guest Editors}

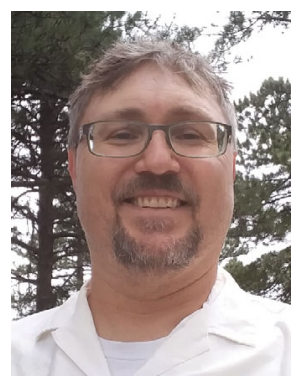

Dr. Steven R. Fassnacht is a Professor of Watershed Science, Department of Ecosystem and Sustainability, Colorado State University. He received his Ph.D. in Civil Engineering from the University of Waterloo, Canada in 2000 after receiving a B.A.Sc. (Civil Engineering-Water Resources) in 1992 and M.A.Sc. (Civil Engineering) in 1995 from the same institution. From 2000 to 2002 he was a Research Associate in the Hydrology and Water Resources Department at the University of Arizona. Since then he has been faculty at Colorado State University. He is currently a Research Fellow with the Cooperative Institute for Research in the Atmosphere, a Senior Research Scientist in the Natural Resources Ecology Laboratory and the Associate Director of the Vertically Integrated Projects Program at CSU. He is also the Water and Environmental Sustainability Coordinator for the Confucius Institute at Colorado State University. Over the 2016-2017 academic year, he was a visiting professor in the Cartography, GIS \& Remote Sensing Department of the Geography Institute at Georg-August-Universität Göttingen in Germany. Dr. Fassnacht's research interests include improving our understanding of snow and cold land hydrological processes into different type of models, the spatial and temporal variability of earth system properties, and the impacts of a changing climate on water resources. To examine how a changing climate affects water resources, his work is integrating human observations of change with station and geospatial information.

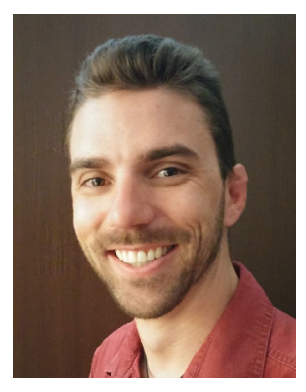

Dr. Ryan Webb is a Research Assistant Professor of Civil Engineering in the Department of Civil, Construction, and Environmental Engineering, University of New Mexico. He received his Ph.D. in Civil Engineering form Colorado State University, USA in 2016. Dr. Webb then obtained a Postdoctoral Fellowship through the US National Science Foundation from 2016-2018, where he was worked at the Institute of Arctic and Alpine Research (INSTAAR) at the University of Colorado in Boulder. Dr. Webb's research interests include snow hydrology, vadose zone hydrology, hydro-geophysics, the impacts of forest fires on hydrology and erosion, open channel hydraulics, and water resource issues in developing countries.

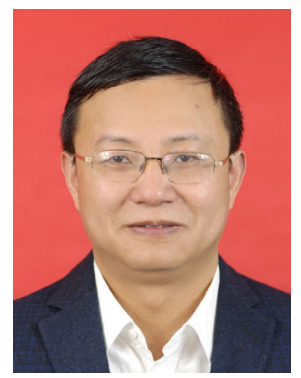

Dr. Mingguo Ma is a Professor of land surface process monitoring and simulation, School of Geographical Sciences, Southwest University. He received his B.Sc. degree (Economic geography and urban and rural regional planning) in 1998 from Lanzhou University, China, and the Ph.D. degree (Cartography and Geographical Information Systems) in 2003 from Cold and Arid Regions Environmental and Engineering Research Institute (CAREERI), Chinese Academy of Sciences (CAS). He had carried out the cooperation research \& post-doctoral fellowship in 2004 from Flemish Institute for Technological Research (Vito) Center for Remote Sensing and Atmospheric Processes (TAP), Belgium. He had worked as a professor at the Laboratory of Remote Sensing and Geospatial Science, CAREERI, CAS from 2009 to 2014. His main research interests have been in ecological remote sensing and land surface process remote sensing. He joined two famous comprehensive experiments at a watershed scale, Watershed Airborne Telemetry Experimental Research (WATER) and Heihe Watershed Airborne Telemetry Experimental Research (HiWATER), and organized the ground-based synchronous and intensive observations. Recently his work mainly focuses on the land surface process observation and analysis using multi-scale observation system and monitoring and simulation using the long time series remote sensing data in Southwest China. 